\title{
NEW UNIVERSAL CURRENT-MODE FILTER USING NON-INVERTING SECOND-GENERATION CURRENT-CONVEYORS
}

\author{
MUHAMMAD TAHER ABUELMA'ATTI AND AAMIR ALAM \\ FAROOQUI
}

King Fahd University of Petroleum and Minerals, Box 203, Dhahran 31261, Saudi Arabia

(Received July 13, 1994; in final form September 7, 1994)

\begin{abstract}
A new universal active current-mode filter with single input and five outputs is presented. The proposed filter avoids the use of feedback in any part of the circuit and uses only one type of second-generation current-conveyors, grounded resistors, and grounded capacitors. The proposed circuit can simultaneously realize lowpass, highpass, bandpass, allpass, and notch biquadratic filter functions.
\end{abstract}

\section{INTRODUCTION}

At present, there is a growing interest in designing current-mode current-conveyorbased active filters. This is attributed to their higher signal bandwidths, greater linearity, and larger dynamic range. ${ }^{1}$ Thus, a number of circuit realizations for universal current-mode filters were proposed. ${ }^{2-11}$ A critical study shows that most of these circuits employ different types of inverting and non-inverting first- and second-generation current conveyors. While some of the proposed circuits use grounded resistors and capacitors, ${ }^{2-7}$ other circuits use floating resistors and/or capacitors. ${ }^{8-11}$ The majority of the proposed circuits can realize all the basic biquadratic filter functions, that is, lowpass, highpass, bandpass, allpass, and notch. However, this cannot be achieved simultaneously. Finally, most of the circuits employ feedback in part of the circuit in order to realize the transfer function required. This may result in instability problems, especially at high frequencies, where the non-idealities of the current-conveyors cannot be ignored.

As an illustrative example, consider the most-recent circuit proposed by Chang. ${ }^{2}$ This circuit uses different types of current conveyors; CCI-, CCI+, CCII-, and $\mathrm{CCII}+$. While the circuit can simultaneously realize lowpass, highpass, and bandpass functions to obtain an allpass function, it is necessary to connect the three output currents. Similarly, to obtain a notch function, it is necessary to connect the highpass and the lowpass output currents. Thus, the five basic filter functions cannot be realized simultaneously. While the circuit has the advantage of using grounded resistors and capacitors, it employs feedback in part of it.

In order to avoid the possible instability problems that may arise due to the employment of feedback, it is necessary to avoid using feedback throughout the whole circuit. Also, it would be attractive for integration if a proposed implementation, avoiding the employment of feedback, can be realized using one type of 
current conveyors only in addition to grounded resistors and capacitors. It is the purpose of this paper to present such a realization.

\section{PROPOSED CIRCUIT}

The proposed circuit is shown in Fig. 1. The circuit uses non-inverting secondgeneration current conveyors $(\mathrm{CCII}+)$ only. Using the standard notation, the CCII+ characteristics can be described by $\mathrm{i}_{x}=\mathrm{i}_{z}, \mathrm{i}_{y}=0, \nu_{x}=\nu_{y}$. Routine analysis of the circuit yields the following transfer functions

$\frac{\mathrm{I}_{o 1}}{\mathrm{I}_{i}}=\frac{\mathrm{Z}_{1} \mathrm{Z}_{3}}{\mathrm{Z}_{2} \mathrm{Z}_{5}}$

$\frac{\mathrm{I}_{o 2}}{\mathrm{I}_{i}}=\frac{\mathrm{Z}_{1} \mathrm{Z}_{3} \mathrm{Z}_{6}}{\mathrm{Z}_{2} \mathrm{Z}_{4} \mathrm{Z}_{7}}$

and

$\frac{\mathrm{I}_{o 3}}{\mathrm{I}_{i}}=\frac{\mathrm{Z}_{1} \mathrm{Z}_{3} \mathrm{Z}_{6}}{\mathrm{Z}_{2} \mathrm{Z}_{4} \mathrm{Z}_{8}}$

Now, if we choose

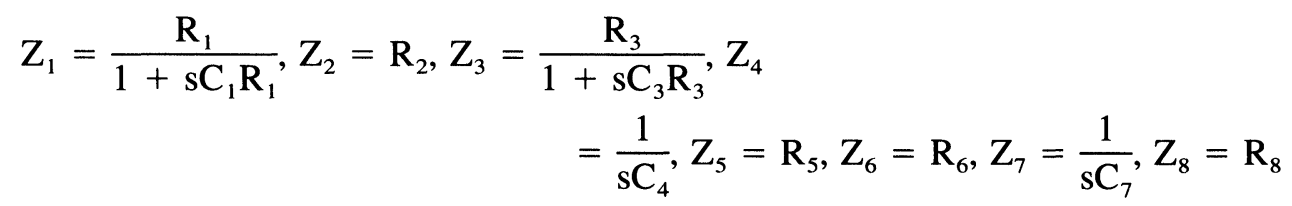

then equations (1)-(3) reduce to

$\frac{I_{o 1}}{I_{i}}=\frac{1 / R_{2} R_{5} C_{1} C_{3}}{s^{2}+s\left(1 / C_{1} R_{1}+1 / C_{3} R_{3}\right)+1 / R_{1} R_{3} C_{1} C_{3}}$

$\frac{I_{o 2}}{I_{i}}=\frac{s^{2} R_{6} C_{4} C_{7} / R_{2} C_{1} C_{3}}{s^{2}+s\left(1 / C_{1} R_{1}+1 / C_{3} R_{3}\right)+1 / C_{1} C_{3} R_{1} R_{3}}$

and

$\frac{I_{o 3}}{I_{i}}=\frac{s_{6} C_{4} / R_{2} R_{8} C_{1} C_{3}}{s^{2}+s\left(1 / C_{1} R_{1}+1 / C_{3} R_{3}\right)+1 / C_{1} C_{3} R_{1} R_{3}}$

Equation (4) corresponds to the transfer function of a lowpass filter, equation (5) corresponds to the transfer function of a highpass filter, and equation (6) corresponds to the transfer function of a bandpass filter. 


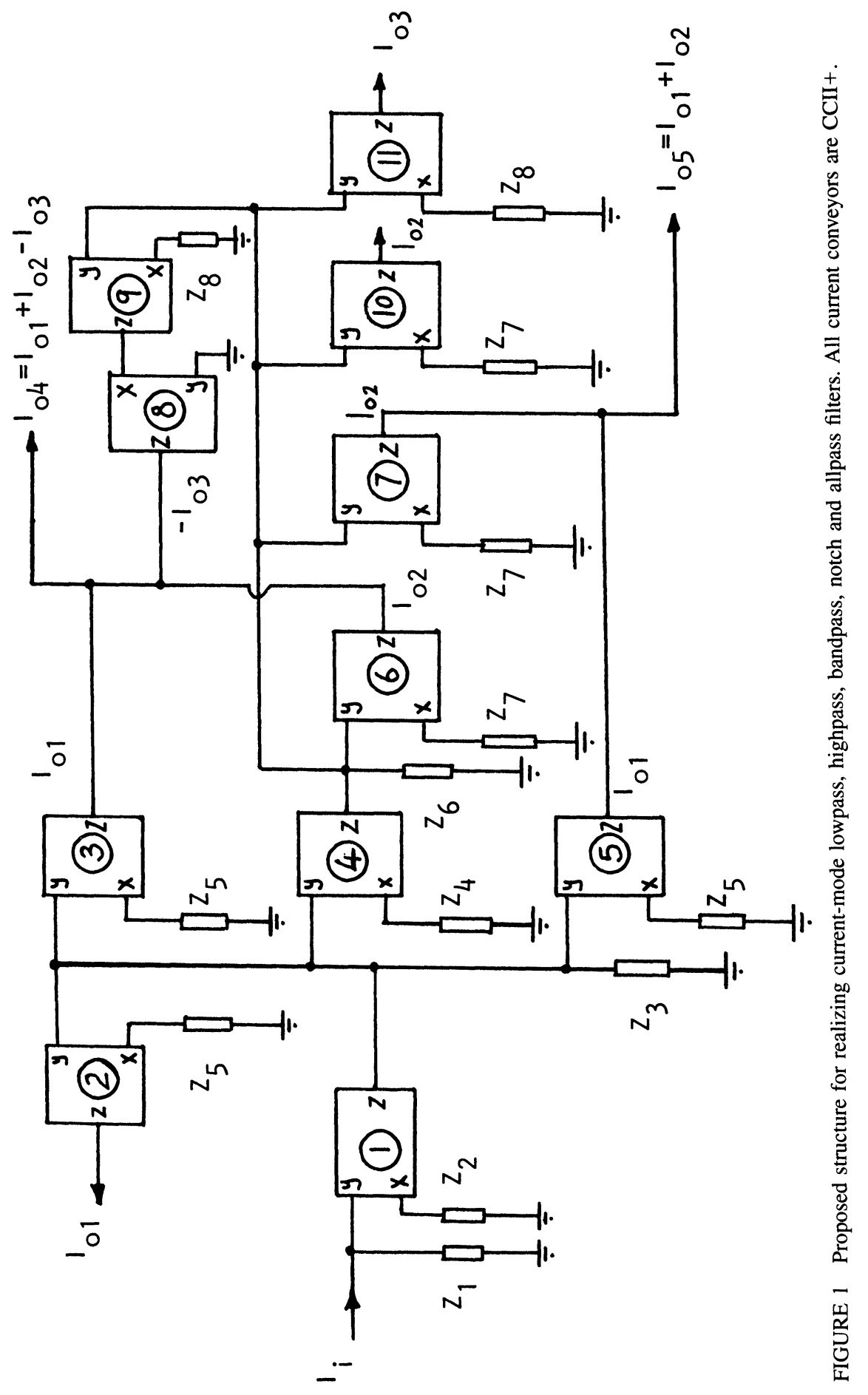


By connecting $\mathrm{I}_{o 1}, \mathrm{I}_{o 2}$, and $-\mathrm{I}_{o 3}$, the resulting current transfer function can be expressed as

$\frac{\mathrm{I}_{o 4}}{\mathrm{I}_{i}}=\frac{\left(\mathrm{C}_{4} \mathrm{C}_{7} \mathrm{R}_{6} / \mathrm{C}_{1} \mathrm{C}_{3} \mathrm{R}_{2}\right)\left(\mathrm{s}^{2}-\mathrm{s}\left(1 / \mathrm{C}_{7} \mathrm{R}_{8}\right)+1 / \mathrm{C}_{4} \mathrm{C}_{7} \mathrm{R}_{5} \mathrm{R}_{6}\right)}{\mathrm{s}^{2}+\mathrm{s}\left(1 / \mathrm{C}_{1} \mathrm{R}_{1}+1 / \mathrm{C}_{3} \mathrm{R}_{3}\right)+1 / \mathrm{C}_{1} \mathrm{C}_{3} \mathrm{R}_{1} \mathrm{R}_{3}}$

If we choose

$1 / \mathrm{C}_{7} \mathrm{R}_{8}=1 / \mathrm{C}_{1} \mathrm{R}_{1}+1 / \mathrm{C}_{3} \mathrm{R}_{3}$

and

$\mathrm{C}_{4} \mathrm{C}_{7} \mathrm{R}_{5} \mathrm{R}_{6}=\mathrm{C}_{1} \mathrm{C}_{3} \mathrm{R}_{1} \mathrm{R}_{3}$

equation (7) reduces to

$\frac{I_{o 4}}{I_{i}}=\frac{\left(R_{1} R_{3} / R_{2} R_{5}\right)\left(s^{2}-s\left(1 / C_{1} R_{1}+1 / C_{3} R_{3}\right)+1 / C_{1} C_{3} R_{1} R_{3}\right)}{s^{2}+s\left(1 / C_{1} R_{1}+1 / C_{3} R_{3}\right)+1 / C_{1} C_{3} R_{1} R_{3}}$

Equation (8) corresponds to the transfer function of an allpass filter. Similarly, by connecting the currents $\mathrm{I}_{o 1}$ and $\mathrm{I}_{o 2}$, the resulting current transfer function can be expressed as

$\frac{I_{o 5}}{I_{i}}=\frac{\left(C_{4} C_{7} R_{6} / C_{1} C_{3} R_{2}\right)\left(s^{2}+1 / C_{4} C_{7} R_{5} R_{6}\right)}{s^{2}+s\left(1 / C_{1} R_{1}+1 / C_{3} R_{3}\right)+1 / C_{1} C_{3} R_{1} R_{3}}$

Equation (9) corresponds to the transfer function of a current-mode elliptic filter with a zero located at

$\omega_{z}^{2}=1 / C_{4} C_{7} R_{5} R_{6}$

and a pole located at

$\omega_{p}^{2}=1 / C_{1} C_{3} R_{1} R_{3}$

From (10) and (11), the zero-pole ratio can be expressed as

$$
\frac{\omega_{z}}{\omega_{p}}=\left(\frac{\mathrm{C}_{1} \mathrm{C}_{3} \mathrm{R}_{1} \mathrm{R}_{3}}{\mathrm{C}_{4} \mathrm{C}_{7} \mathrm{R}_{5} \mathrm{R}_{6}}\right)^{1 / 2}
$$

From (12), one can see that the zero-pole ratio can be adjusted by tuning grounded resistors and/or grounded capacitors. Also, a notch filter can be realized by making the zero-pole ratio equal to unity. 
From (4)-(9), one can see that the parameters $\omega_{o}^{2}$ and $\omega_{o} / Q_{o}$ of the proposed current-mode filter realizations are given by

$\omega_{o}^{2}=1 / \mathrm{C}_{1} \mathrm{C}_{3} \mathrm{R}_{1} \mathrm{R}_{3}$

and

$\frac{\omega_{o}}{\mathrm{Q}_{o}}=1 / \mathrm{C}_{1} \mathrm{R}_{1}+1 / \mathrm{C}_{3} \mathrm{R}_{3}$

From (13) and (14), one can see that the parameters $\omega_{o}$ and $\omega_{o} / \mathrm{Q}_{o}$ can be adjusted by tuning grounded resistors and/or capacitors.

\section{SIMULATION RESULTS}

To verify the theoretical analysis of the proposed circuit, the circuit was simulated using Pspice. The CCII \pm has been simulated using an operational amplifier to-

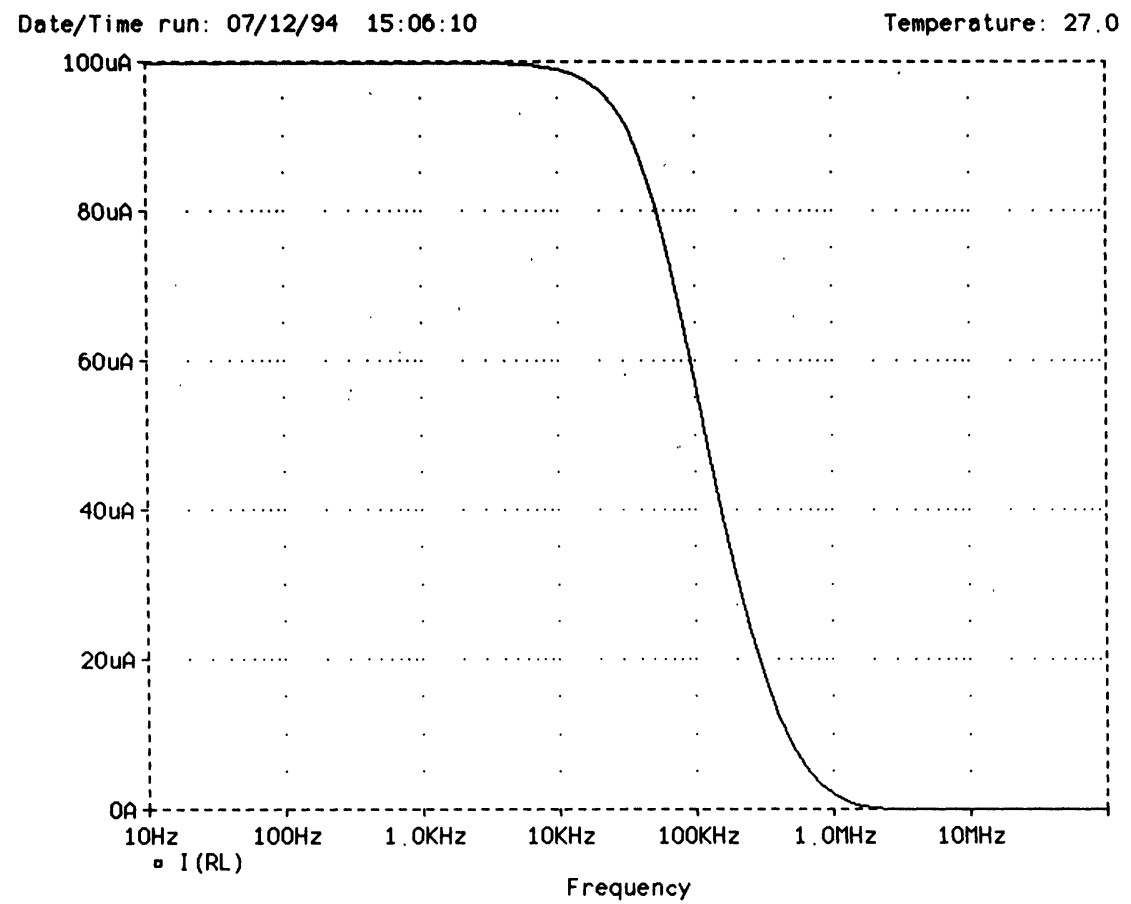

FIGURE 2 Simulated lowpass characteristic obtained from Fig. 1 with $R_{1}=R_{2}=R_{3}=100 \mathrm{k} \Omega, R_{5}=$ $1 k \Omega, C_{1}=22 p F, C_{3}=2.2 p F$. The output current is sensed by connecting a resistance $=1 k \Omega$ at the output of current-conveyor \#2. 


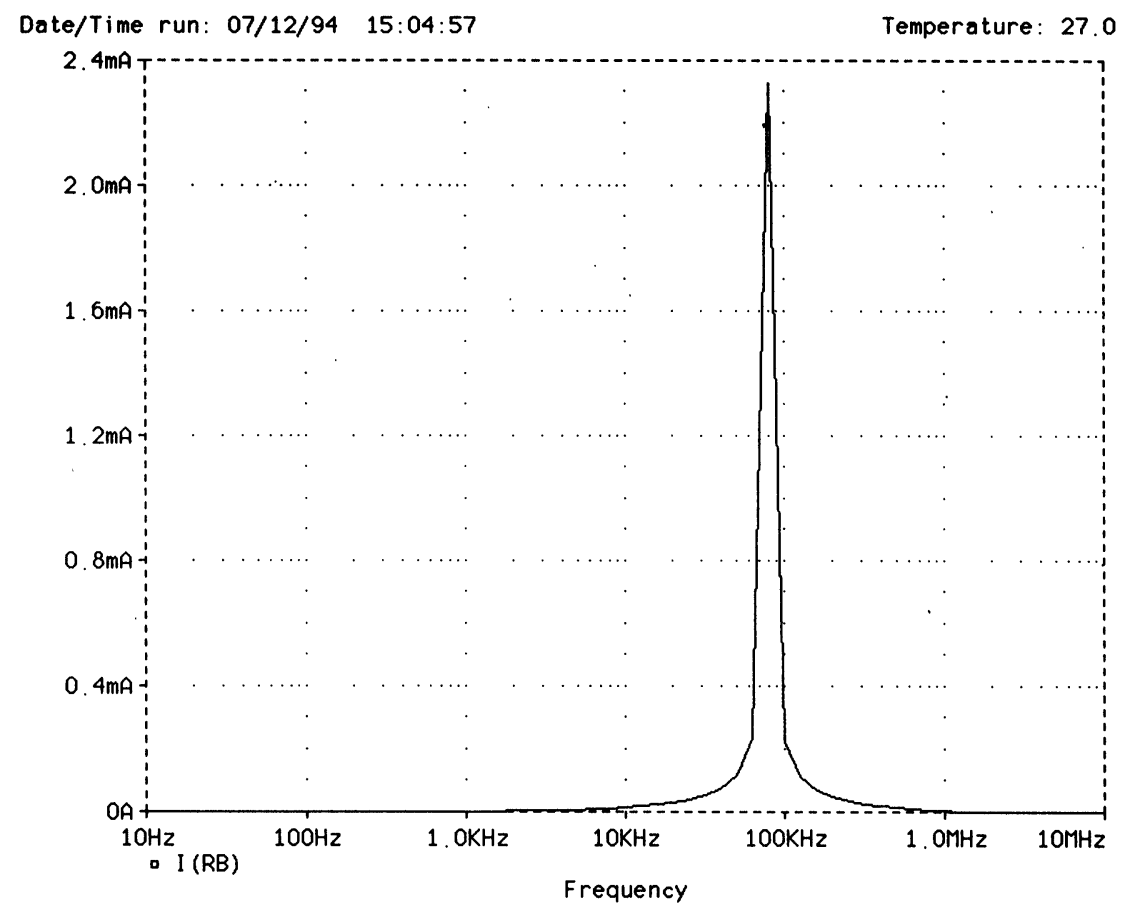

FIGURE 3 Simulated bandpass characteristic obtained from Fig. 1 with $R_{1}=R_{3}=100 \mathrm{k} \Omega, R_{2}=R_{5}$ $=1 k \Omega, R_{6}=1 k \Omega, C_{1}=C_{3}=0.22 p F, C_{4}=22 p F, C_{7}=2.2 p F, C_{8}=22 n F$. The output current is sensed by connecting a load resistance $=1 \mathrm{k} \Omega$ at the output of current-conveyor \#11.

gether with current mirrors composed of transistor arrays. ${ }^{12}$ The results obtained from the lowpass and the bandpass filters are shown in Figs. 2 and 3. These results are in good agreement with the theory presented.

\section{CONCLUSION}

In this paper, a universal current-mode active filter circuit has been presented. The circuit can simultaneously realize all the biquadratic filter sections, that is, the lowpass, the highpass, the bandpass, the allpass, and the notch. The parameters $\omega_{o}$ and $\omega_{o} / \mathrm{Q}_{o}$ can be adjusted by tuning grounded resistors and/or grounded capacitors.

\section{REFERENCES}

[1] G.W. Roberts and A.S. Sedra, All current-mode frequency selective circuits, Electronics Letters, Vol. 25, 1989, pp. 759-761.

[2] C.-M. Chang, Novel universal current-mode filter with single input and three outputs using only five current conveyors, Electronics Letters, Vol. 29, 1993, pp. 2005-2007. 
[3] C.-M. Chang, Universal active current filter with single input and three outputs using CCIIs, Electronics Letters, Vol. 29, 1993, 1932-1933.

[4] C.-M. Chang and P.-C. Chen, Universal active current filter with three inputs and one output using current conveyors, International Journal of Electronics, Vol. 71, 1991, pp. 817-819.

[5] C.-M. Chang and P.-C. Chen, Realization of current-mode transfer function using second-generation current conveyors, International Journal of Electronics, Vol. 71, 1991, pp. 805-815.

[6] Y. Sun and J.K. Fidler, Versatile active biquad based on second-generation current conveyors, International Journal of Electronics, Vol. 76, 1994, pp. 91-98.

[7] C.-M. Chang, C.-C. Chien and H.-Y. Wang, Universal active current filter with three inputs using current conveyors-Part 2, International Journal of Electronics, Vol. 76, 1994, pp. 87-89.

[8] C.-M. Chang, Current-mode lowpass, bandpass and highpass biquads using two CCIIs, Electronics Letters, Vol. 29, 1993, pp. 2020-2021.

[9] C.-M. Chang, Universal active current filters using single second-generation current conveyor, Electronic Letters, Vol. 27, 1991, pp. 1614-1617.

[10] C.-M. Chang, C.-C. Chien and H.-Y. Wang, Universal active current filters using single secondgeneration current conveyor, Electronics Letters, Vol. 29, 1993, pp. 1159-1160.

[11] D.-S. Wu, Y.-S. Hwang, S.-I. Liu and Y.-P. Wu, New multifunction filter using an inverting CCII and a voltage follower, Electronics Letters, Vol. 30, 1994, pp. 551-552.

[12] B. Wilson, High-performance current conveyor implementation, Electronics Letters, Vol. 20, 1984, pp. 990-991. 

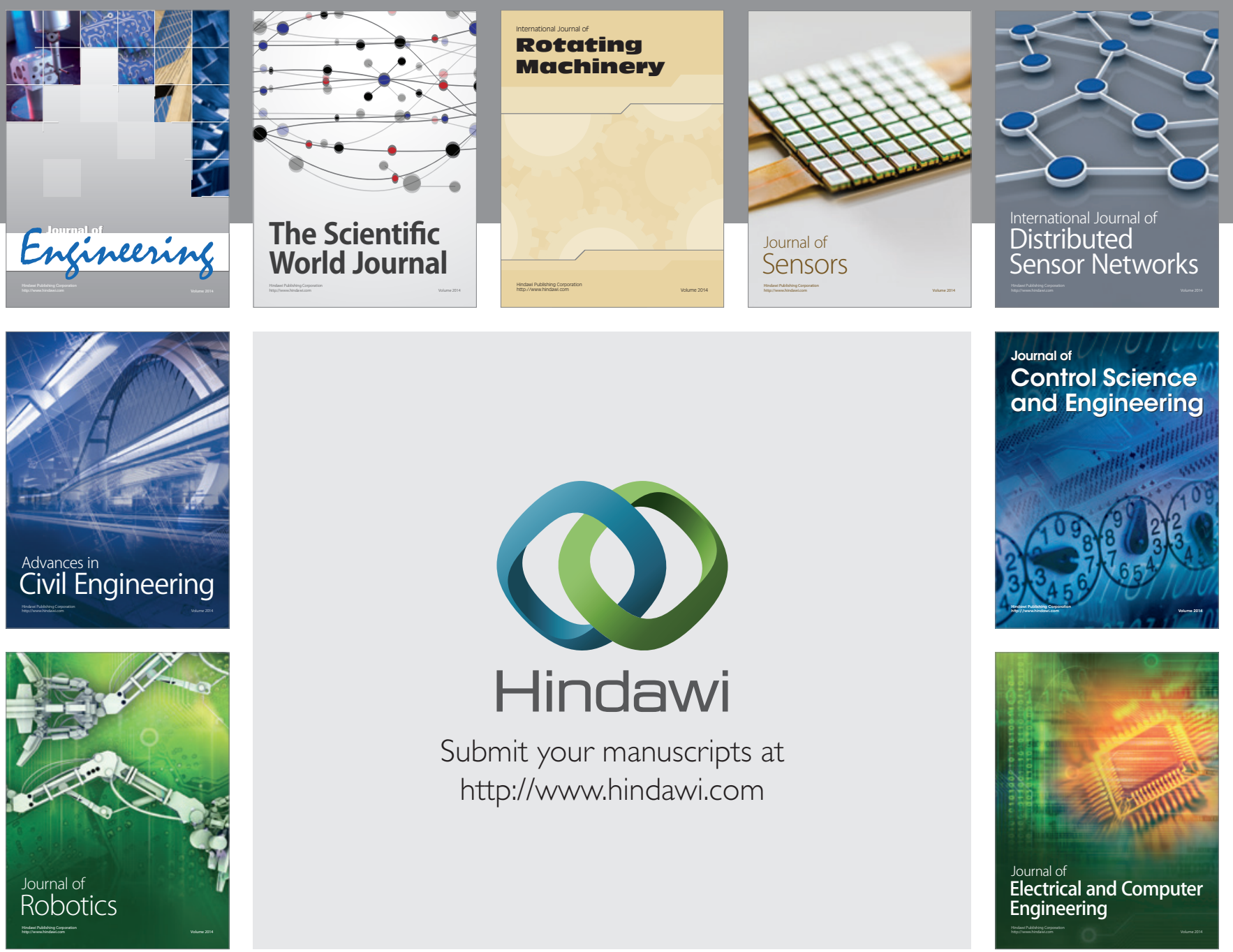

Submit your manuscripts at

http://www.hindawi.com
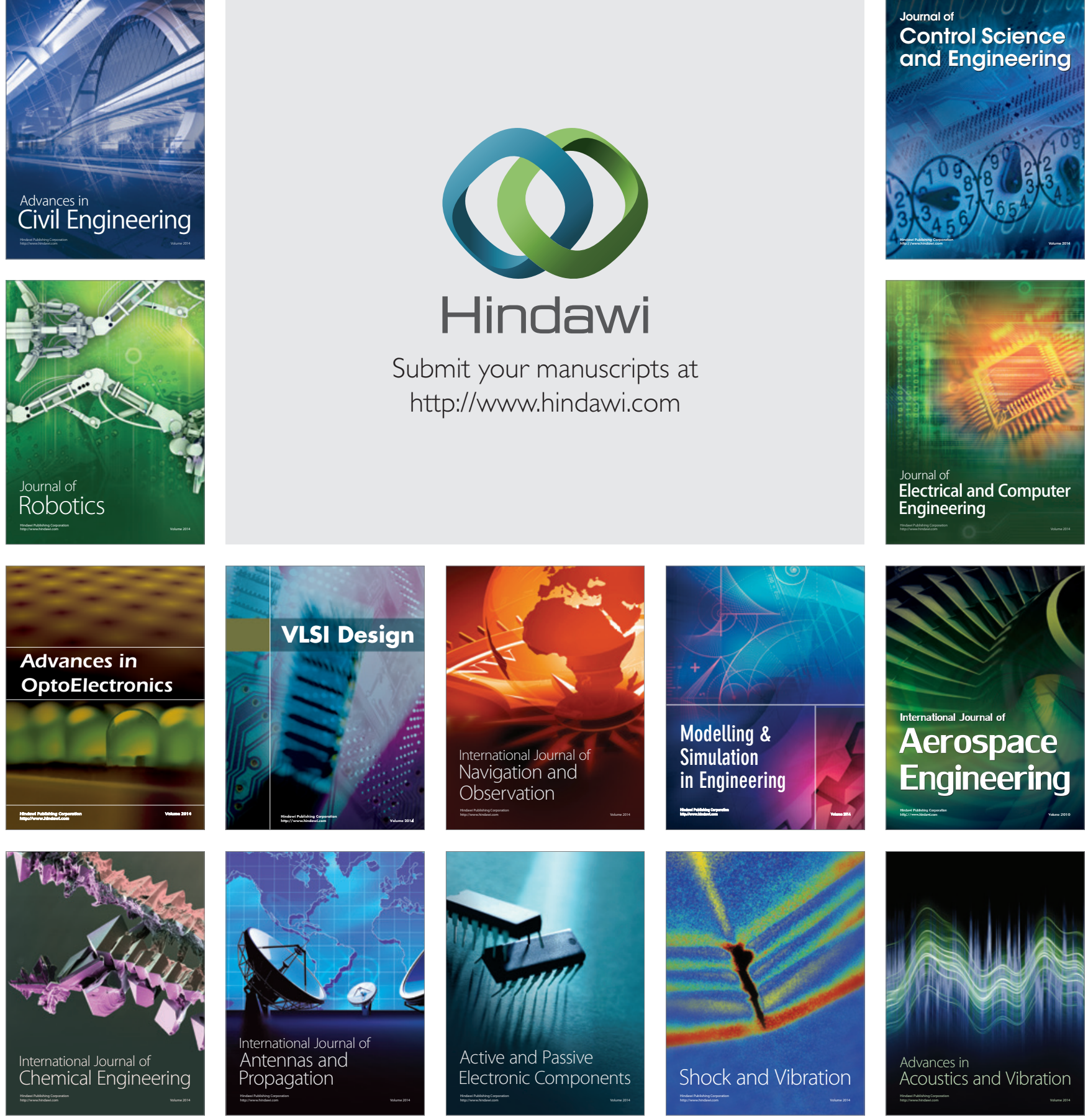